\title{
Virtual care in the pediatric emergency department: a new way of doing business?
}

\author{
Sarah Reid ${ }^{1,2} \cdot$ Maala Bhatt ${ }^{2,3} \cdot$ Roger Zemek $^{1,2} \cdot$ Sandy Tse ${ }^{1,2}$ \\ Received: 31 July 2020 / Accepted: 4 November 2020 / Published online: 18 December 2020 \\ (c) Canadian Association of Emergency Physicians (CAEP)/ Association Canadienne de Médecine d'Urgence (ACMU) 2020
}

\begin{abstract}
Objectives To understand the feasibility, utilization rate, and satisfaction of the first Virtual Pediatric ED (V-PED) in Canada. Methods We conducted a prospective cohort study examining the feasibility and impact of virtual care as an adjunct to in-person emergency care at a tertiary pediatric hospital from May to July 2020. Children ( $<18$ years) from Ontario and Quebec seeking V-PED care were included. A secure, encrypted, video platform within the hospital's electronic medical record was used. Caregivers self-determined appropriateness of V-PED using a standardized online triage questionnaire to request their appointment. The V-PED is directly launched from the patient's chart and the family joins the portal via hyperlink. Outcome measures included the number of V-PED visits, hospital admission rates, and caregiver satisfaction using a 10 -item voluntary post-visit online survey.

Results A total of $1036 \mathrm{~V}-\mathrm{PED}$ visits were seen of which 176 (17.0\%) were referred for further in-person ED assessment, and $8(0.8 \%)$ required hospital admission. Of the 107 completing patient experience surveys (10\% response), most respondents $(69 \%)$ endorsed they "very likely" or "definitely" would have presented in-person to the ED if V-PED were unavailable. Overall satisfaction was rated as excellent (9 or 10 out of 10) in $87 \%$ of respondents.

Conclusion Our novel V-PED is feasible, has high caregiver satisfaction, and can reduce the burden of in-person ED visits. Future work must ensure the safety of emergency virtual care and examine how to increase capacity and integrate V-PED within traditional emergency medicine.
\end{abstract}

Keywords Pediatric $\cdot$ Emergency medicine $\cdot$ Virtual care $\cdot$ COVID-19 $\cdot$ Pandemic

\section{Résumé}

Objectifs Comprendre la faisabilité, le taux d'utilisation et la satisfaction du premier service d'urgence pédiatrique virtuel (V-PED) au Canada.

Méthodes Nous avons mené une étude de cohorte prospective examinant la faisabilité et l'impact des soins virtuels comme complément aux soins d'urgence en personne dans un hôpital pédiatrique tertiaire de mai à juillet 2020. Les enfants $(<18$ ans) de l'Ontario et du Québec cherchant à bénéficier d'une prise en charge par la V-PED ont été inclus. Une plateforme vidéo sécurisée et cryptée a été utilisée dans le dossier médical électronique de l'hôpital. Les soignants ont autodéterminé la

Electronic supplementary material The online version of this article (https://doi.org/10.1007/s43678-020-00048-w) contains supplementary material, which is available to authorized users.

Sarah Reid

sreid@cheo.on.ca

1 Departments of Pediatrics and Emergency Medicine, University of Ottawa, Ottawa, Canada

2 Division of Emergency Medicine, Children's Hospital of Eastern Ontario, 401 Smyth Road, Ottawa, ON K1H 8L1, Canada

3 Department of Pediatrics, University of Ottawa, Ottawa, Canada 
pertinence du V-PED à l'aide d'un questionnaire de triage en ligne normalisé pour demander leur rendez-vous. Le V-PED est directement lancé à partir du dossier du patient et la famille rejoint le portail via un lien hypertexte. Les mesures des résultats comprenaient le nombre de visites de V-PED, les taux d'admission à l'hôpital et la satisfaction des soignants à l'aide d'une enquête en ligne volontaire en 10 points après la visite.

Résultats Au total, 1036 visites de DEP-V ont été effectuées, dont 176 (17,0\%) ont fait l'objet d'une évaluation approfondie en personne aux urgences, et $8(0,8 \%)$ ont nécessité une hospitalisation. Sur les 107 répondants aux enquêtes sur l'expérience des patients (10\% de réponses), la plupart (69\%) ont déclaré qu'ils se seraient "très probablement" ou "certainement" présentés en personne aux urgences si la V-PED n'était pas disponible. La satisfaction globale a été jugée excellente $(9$ ou 10 sur 10) par $87 \%$ des répondants.

Conclusion Notre nouveau V-PED est réalisable, donne une grande satisfaction aux soignants et peut réduire le fardeau des visites en personne aux urgences. Les travaux futurs doivent garantir la sécurité des soins virtuels d'urgence et examiner comment augmenter la capacité et intégrer la V-PED dans la médecine d'urgence traditionnelle.

\section{Clinician's capsule}

\section{What is known about the topic?}

Virtual care has expanded during the COVID-19 pandemic but has not previously been offered to Canadian pediatric emergency department patients.

\section{What did this study ask?}

What is the feasibility, utilization rate, and caregiver satisfaction of the first Virtual Pediatric ED (V-PED) in Canada?

\section{What did this study find?}

This prospective cohort study found that a virtual pediatric emergency department is feasible and associated with high caregiver satisfaction.

\section{Why does this study matter to clinicians?}

Virtual care can lead to a decrease in in-person ED visits and may help to address overcrowding in pediatric EDs.

\section{Introduction}

At the onset of the COVID-19 pandemic, emergency departments (EDs) globally experienced a significant decrease in patients seeking emergency care, with the greatest decline in visits for women and children [1]. Our tertiary pediatric ED (annual census $>75,000$ visits) witnessed a $60 \%$ decrease compared to seasonal norms. While physical distancing, school/daycare closures and recreational-activity cancellations likely decreased the burden of viral illness and injuries, this decrease was also possibly driven by families' desires to minimize the risk of contracting COVID-19 in hospital. Delayed presentations of acute illness to pediatric EDs were reported with associated increases in morbidity [2]. Widespread personal protective equipment shortages required organizations to seek novel solutions for conservation. These challenges inspired our team to develop and evaluate the first Virtual Pediatric ED (V-PED) in Canada. We sought to provide access to urgent pediatric care while avoiding in-person ED visits. The objective of our study was to understand the feasibility and utilization rate of this innovation.

\section{Methods}

We conducted a prospective cohort study examining the feasibility and impact of virtual care as an adjunct to in-person emergency care at a tertiary pediatric hospital in Ottawa, Canada. The V-PED platform was launched on May 4, 2020 and data were collected through July 7, 2020. All children from Ontario and Quebec, aged 0-18 years, seeking care on V-PED were included.

Our intervention adapted a secure encrypted video platform (Zoom for Healthcare ${ }^{\mathrm{TM}}$ embedded into Epic ${ }^{\mathrm{TM}}$ electronic medical record; Privacy Impact Assessment/Security Threat and Risk Assessment completed) to create V-PED. In our self-referral model, caregivers determine whether V-PED is appropriate for their child by reviewing an online checklist based upon hospital recommendations for using the ED (Appendix 1). If their child is experiencing a high-acuity complaint (e.g., fever in an infant $<3$ months), families are directed to present for an in-person ED assessment. If deemed V-PED appropriate, the caregiver submits a standardized questionnaire including demographics, chief complaint, and past medical history. A registration clerk contacts the family (within $30 \mathrm{~min}$ ) to book the next available V-PED appointment, emailing a link with log-in instructions. Thirty-minute appointments are offered from 9 a.m. to 9 p.m., 7 days per week. The pediatric emergency physician launches V-PED directly from the patient's chart and families join the portal with their device. V-PED patients requiring testing (e.g., urinalysis) or in-person evaluation are referred to the ED for a nurse-only or regular ED visit, respectively. 
Outcome measures included the number of V-PED visits, hospital admission rates, unscheduled ED visits $<72 \mathrm{~h}$ post-VPED, and caregiver satisfaction using a 10 -item voluntary postvisit REDCap online survey. Experienced pediatric emergency nurses conducted postlaunch quality assurance telephone follow-up for two-weeks. Subsequently, patient experience surveys were delivered to caregivers via email, appended to discharge instructions. Given the exploratory nature of our study, descriptive statistics were calculated for all variables in frequencies and percentages. This study was exempt from REB approval as it was undertaken for quality improvement.

\section{Results}

In the initial 2-months of the program, there were 1036 V-PED visits ( $76 \%$ of available appointments). Table 1 summarizes patient characteristics, chief complaints and disposition of all V-PED patients. Thirteen percent of Ontario users resided $>50 \mathrm{~km}$ from our hospital and $14 \%$ were from Quebec. A total of 176/1036 patients (17.0\%) were referred for in-person ED assessment/investigations, and 8/1036 $(0.8 \%)$ were admitted. A further $80 / 1036$ patients $(7.7 \%)$ had an unscheduled ED visit within $72 \mathrm{~h}$ of their V-PED visit. CTAS categories for all patients seen in the ED over the study period are included in Table 1.

Caregivers reported high satisfaction with V-PED during post-visit telephone interviews, as they "had been unable to see their primary care provider", "were saved the drive in", and "loved that [they] didn't have to be in contact with other sick patients". Many families requested that V-PED continue post-COVID.

One hundred and seven online patient experience postvisit surveys were completely independent of the medical provider (10\% response rate). Forty-one percent of respondents tried to contact their primary care provider prior to accessing the V-PED service. Most respondents (69\%) stated that they "very likely" or "definitely" would have presented in-person to the ED had they not been able to access virtual care. All respondents agreed that the V-PED visit was able to address their concerns, that the technology worked well, and that they would use V-PED in the future. Using a 0-10 scale, overall satisfaction was rated as excellent (9 or 10) in $86.9 \%$ of respondents, with none reporting their satisfaction $<7$. Table 1 summarizes additional quality metrics including unscheduled visits and antibiotic prescriptions.

\section{Discussion}

Our novel V-PED is feasible with high caregiver satisfaction, reducing the in-person visit burden. While no Canadian studies have examined the use of pediatric ED virtual care, the majority of US virtual care studies describe teleconsultation between non-pediatric and pediatric EDs to facilitate clinical care and/or transport [3, 4]. Recently, a US pediatric hospital reported high caregiver satisfaction with their direct-to-consumer virtual urgent care program, with a similar referral rate (12\%) and $0.02 \%$ admission rate [5]. The expansion of virtual care during the pandemic has been well documented [6], and encouraged through government policy and additional funding [7]. EDs across Canada have expressed interest in our program and many are now launching their own virtual care services.

Our model departs significantly from traditional in-person pediatric emergency care. The absence of triage precludes risk-stratification of the patient. Further, while many maneuvers can be adapted to video, the conventional pediatric physical exam is impossible. Due to these limitations, some patients are directed by the treating physician to present for an in-person ED assessment. Interestingly, less than $20 \%$ of patients required in-person assessment and two-thirds of survey respondents reported that they would have otherwise gone to the ED for care. While we are not able to extrapolate given the $10 \%$ response rate of the caregiver survey, these early data may suggest a trend whereby V-PED has the potential to decrease in-person ED utilization. Although $\mathrm{V}$-PED is hosted on an encrypted platform, patients/caregivers receive standardized language regarding the possibility of a privacy breach and thus must provide verbal consent. For this model of care, users require access to an electronic device capable of operating the application, thus limiting $\mathrm{V}$-PED access for some families. V-PED is only offered in English and French, with no current option for live translation. Finally, given the low number of patients seen to date, we cannot definitively comment on the safety of V-PED as this will require more surveillance. Despite this limitation, however, there has been a low rate of referral to the ED, low admission rate, and no identified patient safety concerns. Finally, V-PED was possible due to reduced patient volumes during the pandemic which allowed redirection of existing ED staffing resources to this initiative; challenges to long-term feasibility exist from a financial and staffing perspective.

In the pre-pandemic era, pediatric ED overcrowding in Canada threatened patient safety and quality of care [8]. In contrast to the boarding of admitted patients in adult EDs [9], pediatric ED overcrowding is predominantly driven by high volume of low-acuity visits [10,11]. Many caregivers utilize the pediatric ED for issues that could be addressed by primary care; our preliminary V-PED data reveals a similar phenomenon. Providing timely access to medical care from the comfort of home may further encourage caregivers to seek advice for issues more appropriately managed by primary care without the normal barriers of wait-times or travel. 
Table 1 V-PED patient and appointment characteristics (May 4-July 7, 2020)

\begin{tabular}{|c|c|}
\hline & $n(\%)$ \\
\hline V-PED appointment days & 65 \\
\hline Patients assessed & 1036 \\
\hline Appointments per day, median (IQR) & $16(14,18)$ \\
\hline Age, median (IQR) & 3 years $(1,7)$ \\
\hline Sex, male & $532(51.4)$ \\
\hline Primary care provider, yes & $863(83.3)$ \\
\hline Ontario patients & $883(85.2)$ \\
\hline$>50 \mathrm{~km}$ from Ottawa center & $113(12.8)$ \\
\hline Quebec patients & $146(14.1)$ \\
\hline$>50 \mathrm{~km}$ from Ottawa center & $9(6.2)$ \\
\hline \multicolumn{2}{|l|}{ Chief complaint } \\
\hline Skin condition/rash & $253(24.4)$ \\
\hline Injury & $176(17.0)$ \\
\hline Fever & $159(15.3)$ \\
\hline Gastrointestinal complaints & $157(15.2)^{*}$ \\
\hline Genito-urinary complaints & $59(5.7)^{*}$ \\
\hline Respiratory complaints & $41(4.0)^{*}$ \\
\hline Mental health & $15(1.4)$ \\
\hline Other & $176(17.0)$ \\
\hline Antibiotic prescription & $89(8.6)$ \\
\hline Referral to ED from V-PED for an in-person MD assessment or nurse-only visit & $176(17.0)$ \\
\hline CTAS 1 & $0(0.0)$ \\
\hline CTAS 2 & $5(2.8)$ \\
\hline CTAS 3 & $97(55.1)$ \\
\hline CTAS 4 & $42(23.9)$ \\
\hline CTAS 5 & $32(18.2)$ \\
\hline Referral to ED for nurse-only visit for testing & $21(11.9)$ \\
\hline Referral to ED for an in-person assessment and admitted & $8(4.5)$ \\
\hline Time elapsed from V-PED visit to ED arrival in minutes, median (IQR) & $102.5(71.3,169.8)$ \\
\hline Unscheduled visit to ED $<72 \mathrm{~h}$ post-V-PED & $80(7.7)$ \\
\hline CTAS 1 & $0(0.0)$ \\
\hline CTAS 2 & $2(2.5)^{* *}$ \\
\hline CTAS 3 & $35(43.8)$ \\
\hline CTAS 4 & $26(32.5)$ \\
\hline CTAS 5 & $17(21.2)$ \\
\hline Unscheduled visit to $\mathrm{ED}<72 \mathrm{~h}$ post-V-PED and admitted & $0(0)$ \\
\hline Total in-person ED visits & 7646 \\
\hline CTAS 1 & $54(0.7)$ \\
\hline CTAS 2 & $601(7.9)$ \\
\hline CTAS 3 & $3497(45.7)$ \\
\hline CTAS 4 & $2324(30.4)$ \\
\hline CTAS 5 & $1170(15.3)$ \\
\hline Total hospital admissions & $496(6.5)$ \\
\hline Total hospital admissions from V-PED & $8(0.8)$ \\
\hline
\end{tabular}

$* \pm$ Fever

**Reducible inguinal hernia with crying in infant; seasonal allergies with new asthma exacerbation 


\section{Conclusion}

V-PED achieves our objective of ensuring access to urgent pediatric care during the pandemic and offers caregivers a highly valued alternative. Future work must ensure the safety of emergency virtual care and examine how to increase capacity and integrate V-PED within traditional emergency medicine. Interest in expanding this model is being explored nationally and may help divert low-acuity visits in the periand post-pandemic future.

\section{Compliance with ethical standards}

Conflict of interest MB declares competitively funded research grants from Physician Services Incorporated (PSI) Foundation, CHEO Foundation and the Ontario Government. No commercial conflicts of interest to disclose. RZ declares competitively funded research grants from Canadian Institutes of Health Research (CIHR), Ontario Neurotrauma Foundation (ONF), Physician Services Incorporated (PSI) Foundation, CHEO Foundation, Ontario Brain Institute (OBI), and Ontario SPOR Support Unit (OSSU), National Football League (NFL), and Clinical Research Chair in Pediatric Concussion from University of Ottawa. No commercial conflicts of interest to disclose. SR and ST have nothing to disclose.

\section{References}

1. Hartnett KP, Kite-Powell A, DeVies J, Coletta MA, Boehmer TK, Adjemian J, et al. Impact of the COVID-19 pandemic on emergency department visits-United States, January 1, 2019-May 30, 2020. MMWR Morb Mortal Wkly Rep. 2020;69:699-704.
2. Lazzerini M, Barbi E, Apicella A, Marchetti F, Cardinale F, Trobia G. Delayed access or provision of care in Italy resulting from fear of COVID-19. Lancet Child Adolesc Health. 2020;4(5):e10-1.

3. Brova M, Boggs KM, Zachrison KS, Freid RD, Sullivan AF, Espinola JA, et al. Pediatric telemedicine use in United States emergency departments. Acad Emerg Med. 2018;25(12):1427-32.

4. Cotton J, Bullard-Berent J, Sapien R. Virtual pediatric emergency department telehealth network program: a case series. Pediatr Emerg Care. 2020;36(5):217-21.

5. Kim JW, Friedman J, Clark S, Hafeez B, Listman D, Lame M, et al. Implementation of a pediatric emergency telemedicine program. Pediatr Emerg Care. 2020;36(2):e104-7.

6. Webster P. Virtual health care in the era of COVID-19. Lancet. 2020;395:1180-1.

7. Info Bulletin. Changes to the schedule of benefits for physician services (schedule) in response to COVID-19 influenza pandemic effective March 14, 2020. Available:https://www.health.gov.on.ca/ en/pro/programs/ohip/bulletins/4000/bul4745.aspx (accessed 2020 September 21).

8. Doan Q, Wong H, Meckler G, Johnson D, Stang A, Dixon A, et al. The impact of pediatric emergency department crowding on patient and health care system outcomes: a multicentre cohort study. CMAJ. 2019;191(23):e627-35.

9. Affleck A, Parks P, Drummond A, Rowe BH, Ovens HJ, et al. Emergency department overcrowding and access block. CJEM. 2013;15(6):359-70.

10. Doan Q, Genius ED, Yu A. Trends in use in a Canadian pediatric emergency department. CJEM. 2014;16(5):405-10.

11. Farion KJ, Wright M, Zemek R, Neto G, Karwowska A, Tse S, et al. Understanding low-acuity visits to the pediatric emergency department. PLoS ONE. 2015;10(6):e0128927. 